\title{
Neuroleptic-induced deficit syndrome in bipolar disorder with psychosis
}

\author{
This article was published in the following Dove Press journal: \\ Neuropsychiatric Disease and Treatment \\ 2 February 2016 \\ Number of times this article has been viewed
}

\author{
Satoshi Ueda' \\ Takeshi Sakayori' \\ Ataru Omori ${ }^{2}$ \\ Hajime Fukuta ${ }^{3}$ \\ Takashi Kobayashi ${ }^{3}$ \\ Kousuke Ishizaka' \\ Tomoyuki Saijo ${ }^{4}$ \\ Yoshiro Okubo' \\ 'Department of Neuropsychiatry, \\ Nippon Medical School, Tokyo, Japan; \\ ${ }^{2}$ Tamachuo Hospital, Tokyo, Japan; \\ ${ }^{3}$ Kurumegaoka Hospital, Tokyo, Japan; \\ ${ }^{4}$ Saijo Clinic, Tokyo, Japan
}

\begin{abstract}
Neuroleptics can induce not only physical adverse effects but also mental effects that produce deficit status in thought, affect, cognition, and behavior. This condition is known as neuroleptic-induced deficit syndrome (NIDS), which includes apathy, lack of initiative, anhedonia, indifference, blunted affect, and reduced insight into disease. Although this old concept now appears almost forgotten, neuroleptics, whether typical or atypical, can make depression or bipolar disorder resemble other more refractory conditions, readily leading to mistaken diagnosis and inappropriate treatment. The authors describe three cases of NIDS superimposed on depressive phase in bipolar disorder with psychosis, where the attending psychiatrist's failure to recognize NIDS prevented patients from receiving effective treatment and achieving remission. All cases achieved remission after reduction of neuroleptics and intensive therapy, including electroconvulsive therapy, for bipolar depression. The concept of NIDS was originally introduced for schizophrenia, and it has rarely been highlighted in other diseases. In recent years, however, atypical antipsychotics are being more often administered to patients with bipolar disorder. Psychiatrists, therefore, should also remember and exercise caution regarding NIDS in the pharmacotherapy of bipolar disorder with and without psychosis. The authors believe that the concept of NIDS needs to be reappraised in current psychiatry.
\end{abstract}

Keywords: neuroleptic-induced deficit syndrome (NIDS), bipolar disorder, psychosis, atypical antipsychotics, electroconvulsive therapy

\section{Introduction}

It is well known that neuroleptics can induce physical adverse effects such as extrapyramidal symptoms and oversedation, but they can also induce mental adverse effects, which involve deficit status in thought, affect, cognition, and behavior, the typical phenomena of which are apathy, lack of initiative, anhedonia, indifference, blunted affect, and reduced insight into disease. They very much resemble negative symptoms of schizophrenia. Such effects are known as neuroleptic-induced deficit syndrome (NIDS), which was proposed in order to promote interest in the mental adverse effects of neuroleptics by Lader ${ }^{1}$ and Lewander. ${ }^{2}$ Their original intention was that NIDS should be strictly differentiated from disease-related negative symptoms in schizophrenia patients taking typical antipsychotics. Recent studies, ${ }^{3,4}$ however, have indicated that some atypical antipsychotics also might well induce NIDS. This old concept appears almost forgotten in current psychiatry.

NIDS also occurs in patients with psychiatric disorders other than schizophrenia, often making them resemble schizophrenia, chronic psychiatric condition, or even dementia. ${ }^{5}$ This means that a disease with better prognosis, such as depression or bipolar disorder, might be misdiagnosed as other refractory disorders, which would then prevent patients from receiving optimal treatment. We describe three cases of NIDS in bipolar
Correspondence: Satoshi Ueda Department of Neuropsychiatry, Nippon Medical School, I-I-5 Sendagi, Bunkyo-ku, Tokyo II3-8603, Japan $\mathrm{Tel}+8|338222| 3 \mid$

Fax $+8 I 358146287$

Email sat333@nms.ac.jp 
disorder with psychosis, where the attending psychiatrists' failure to recognize NIDS prolonged their treatment course, delaying remission. This study was deemed exempt from full review according to the ethics committee of Nippon Medical School, Japan as this was a naturalistic study. Written, informed consent was obtained from all patients.

\section{Case I}

A 50-year-old married man with no personal and family history of psychiatric disease had recurrent depression and psychotic mania since his 20 s and visited a psychiatric hospital. He ran a retail trade after graduation from university. From his late 30s, he had several relapses. Flight of ideas, irritability, and grandiose delusion occurred in his manic periods, while psychomotor inhibition, hypothymia, and self-reproach occurred in his depressive periods. He was usually treated with fluvoxamine and low-dose haloperidol, but developed mania with psychosis at age 48 and was hospitalized. Haloperidol was increased to $9 \mathrm{mg} / \mathrm{d}$, and risperidone at $12 \mathrm{mg} / \mathrm{d}$ was added to fluvoxamine at $75 \mathrm{mg} / \mathrm{d}$. Psychotic mania was resolved, but apathy, lack of initiative, blunted affect, and anxiety appeared, while his appetite was still good. He talked with an expressionless, low voice, and walked slowly dragging his feet with a slouched posture. Muscle rigidity and tremor were mild. Although he developed neither mania nor agitation, he often complained that his future was hopeless and that he felt lonely. Thus, he was suspected of chronic anxious depression.

After 2 years of no improvement, he went to a general hospital. He appeared strangely indifferent to his current illness and potential treatment. Physical examinations detected no abnormalities. Diagnosed with bipolar disorder with psychosis, he was successfully treated with nine sessions of electroconvulsive therapy (ECT). Antipsychotics were greatly reduced to risperidone at only $3 \mathrm{mg} / \mathrm{d}$. He became lively and free of anxiety. His actions, including walking, became as quick and smooth as before. Lithium carbonate at $800 \mathrm{mg} / \mathrm{d}$ and valproate at 1,000 mg/d were started. He successfully returned to work, and has remained in remission for 6 years.

\section{Case 2}

A 49-year-old married woman with no personal and family history of psychiatric disease had worked steadily for a company. After a month of extravagant living, she complained of depressive mood and inability to cook, eat, and sleep. She also complained that a tsunami would come and that the whole world would be destroyed. This was followed by a period of delusion of possession. She was admitted to the psychiatry department of a hospital. Five sessions of ECT improved her psychosis, but not the depression. Suspected of schizoaffective disorder at first, she was given blonanserin at $12 \mathrm{mg} / \mathrm{d}$. Reduced initiative, apathy, and blunted affect developed. Because neuropsychological tests indicated reduced memory retention, inhibited reaction, and change in character from being a methodical to an untidy person, she was suspected of having frontotemporal dementia. She was discharged, but she could not work in the house or at her workplace, as she was demonstrating great anxiety and little vitality.

After 8 months of no change, she was admitted to another hospital. Detailed examinations revealed no organic abnormalities except moderate extrapyramidal symptoms. She moved slowly, showed very little facial expression, had poor insight into her disease, and displayed reduced desire to improve. She underwent 12 sessions of ECT, and blonanserin was stopped. She gradually became lively, motivated, and rich in emotional expression, with absence of extrapyramidal symptoms. She recovered her originally tidy personality. Lithium carbonate at $800 \mathrm{mg} / \mathrm{d}$ and quetiapine at $200 \mathrm{mg} / \mathrm{d}$ have maintained her in remission for 5 years.

\section{Case 3}

After his divorce, a 42-year-old man with no personal and family history of psychiatric disease, showing a lack of motivation and suicidal ideation, visited the psychiatric department in a hospital, and took antidepressants for only 2 weeks. He had successfully run an independent business since his late 20s. At age 46, he relapsed into a depressive state and revisited the same department. He complained of a feeling of having worms on his back and of being watched by someone from outside his home. He was suspected of suffering from some psychosis in addition to depression. Olanzapine at $10 \mathrm{mg} / \mathrm{d}$ was started and increased to $20 \mathrm{mg} / \mathrm{d}$. His symptoms remained unresolved. He withdrew progressively and developed blunted affect and poor rapport with others. At every examination in the hospital, he only complained of insomnia, showing poor speech, thought, and responsiveness. Because these conditions were considered to be natural negative symptoms of schizophrenia, he was diagnosed with schizophrenia. The prescribed neuroleptics were changed from olanzapine to risperidone $6 \mathrm{mg} / \mathrm{d}$, and then risperidone was changed to the combination of aripiprazole at $12 \mathrm{mg} / \mathrm{d}$, levomepromazine (150 $\mathrm{mg} / \mathrm{d}$ at the maximum), and quetiapine $(500 \mathrm{mg} / \mathrm{d}$ at the maximum); but they had no effect.

At age 52, his diagnosis was changed to depression by new attending psychiatrists, because they considered that 
Table I Clinical profile

\begin{tabular}{lllll}
\hline Case & $\begin{array}{l}\text { Sex/age } \\
\text { (years) }\end{array}$ & $\begin{array}{l}\text { AP associated with } \\
\text { NIDS }(\mathbf{m g})\end{array}$ & $\begin{array}{l}\text { Time to recover } \\
\text { from NIDS }\end{array}$ & $\begin{array}{l}\text { Pharmacotherapy after } \\
\text { NIDS (mg) }\end{array}$ \\
\hline 1 & M/50 & HPD 9, RIS I2 & 2 years & Li 800, VPA I000 \\
2 & F/49 & BNS I2 & 10 months & Li 800, QTP 200 \\
3 & M/52 & OLZ I0-20/QTP 500, & 6 years & MTZ 45, QTP 200 \\
\hline
\end{tabular}

Abbreviations: AP, antipsychotics; NIDS, neuroleptic-induced deficit syndrome; HPD, haloperidol; RIS, risperidone; Li, lithium carbonate; VPA, valproate; BNS, blonanserin; QTP, quetiapine; OLZ, olanzapine; LPZ, levomepromazine; APZ, aripiprazole; MTZ, mirtazapine; M, male; F, female.

none of his symptoms were typical of schizophrenia and because the onset and progression of his illness was more likely to correspond to the treatment course of depression than to that of schizophrenia. Neuroleptics were drastically reduced: quetiapine at $500 \mathrm{mg} / \mathrm{d}$ was decreased to $200 \mathrm{mg} / \mathrm{d}$, while $150 \mathrm{mg} / \mathrm{d}$ of levomepromazine and $12 \mathrm{mg} / \mathrm{d}$ of aripiprazole were stopped. Mirtazapine was administered up to $45 \mathrm{mg} / \mathrm{d}$. He gradually became lively and active. His speech and response on examinations also became more organized and smooth. Hallucinations and delusions were entirely absent. He started a part-time job after 6 years of unemployment. A year later, however, he showed inflated self-esteem and exaggerated elation and became engaged in unrestrained business activities. Mirtazapine was stopped, quetiapine was increased to $350 \mathrm{mg} / \mathrm{d}$, and his mood and behavior became normal.

Table 1 shows the clinical profiles of three cases.

In Cases 1 and 2, ECT at the second hospital, with bilateral frontotemporal electrode placement, was performed three times a week using a Thymatron System IV briefpulse square-wave apparatus (Somatics, LLC, Lake Bluff, IL, USA). Stimulus dosing was done according to "Clinical Manual of Electroconvulsive Therapy". ${ }^{6}$ Thiamylal or propofol was intravenously administered as anesthetic agent, and succinylcholine was given as muscle relaxant.

\section{Discussion}

These three cases appeared to exhibit deficit status superimposed on the depressive phase. The deficit status was probably induced by several kinds of potent neuroleptics, and this condition was identified as NIDS. The major NIDS in these cases included apathy, lack of initiative, blunted affect, indifference, poor insight into disease, and reduced desire to improve. It had not been recognized that these symptoms were neuroleptic-induced, superimposed symptoms. All three cases presented good reasons for a diagnosis of bipolar disorder: Cases 1 and 2 had exhibited both manic and depressive states before admission, and Case 3 exhibited depressive state with psychosis for years, followed by a manic state that was not resolved by discontinuation of antidepressant. However, they were described as appearing like several refractory conditions with poorer prognosis. Case 1 was falsely suspected of chronic depression, Case 2 of frontotemporal dementia, and Case 3 of chronic schizophrenia. NIDS may well have masked the patients' original symptoms and seemingly changed their psychopathology. The attending psychiatrist's failure to recognize NIDS resulted in persistent inadequate treatment and delayed remission. After NIDS was treated with reduction of neuroleptics and intensive therapy, including ECT, for bipolar depression, all cases eventually had remission.

Once patients, who have had psychosis, are suspected of refractory diseases, neuroleptics are very often not discontinued in case of possible relapse, as shown in the present cases. Swartz and Shorter ${ }^{7}$ warned that antipsychotic drugs are two-edged swords: at first swing they cut psychosis, but when taken in sufficient duration (2 years in young patients, 2 months in elderly) antipsychotic drugs cause psychosis or depression. Then the antipsychotic is continued to cut the symptoms it brought on.

Patients with NIDS, however, do not always improve with only discontinuation of neuroleptics, because the discontinuation may actually again elicit their original symptoms such as psychosis or mania. In such cases, ECT may be a very useful and effective option, as observed in Cases 1 and 2. After ECT, maintenance pharmacotherapy for bipolar disorder, and not only for psychosis, must be intensively undertaken.

The concept of NIDS was proposed more than 20 years ago with the aim of differentiating it from negative symptoms in schizophrenia. Some attention has long been paid to this concept when treating schizophrenia patients, where the subjective dysphoric response to neuroleptics and negative influence on their well-being have been focused on. ${ }^{8,9}$ However, there have been only a few reports in the literature on NIDS developing in diseases other than schizophrenia. Among those rare but valuable studies is a case report by Machida et al, ${ }^{5}$ where the authors' recognition of NIDS allowed a patient with obsessive-compulsive disorder to be successfully 
treated. As observed in the cases discussed in the present study, NIDS seems much more likely to occur in patients with psychotic bipolar disorder for whom neuroleptics tend to be more readily prescribed. On the other hand, in the treatment of nonpsychotic bipolar disorder or depression, among neuroleptics, atypical antipsychotics have very often been administered in both labeled and off-labeled use or as augmentation. In recent years, atypical antipsychotics have been appearing one after another as new, better-tolerated agents. These "milder" neuroleptics are more often being administered to patients with bipolar disorder. Psychiatrists, therefore, need to remember and exercise caution concerning NIDS in the pharmacotherapy of bipolar disorder.

NIDS has been considered to be pharmacologically caused by the inhibition of the central dopaminergic reward system; dopamine $\mathrm{D}_{2}$ receptor antagonism of antipsychotics may reduce activation of the system. ${ }^{9}$ Moreover, the specific sedative effects mediated via its antagonism may cause inactivity, apathy, and indifference, related to some extrapyramidal symptoms. ${ }^{2}$ Although atypical antipsychotics show a weaker binding to dopamine $\mathrm{D}_{2}$ receptors, recent studies have presented evidence that some potent atypical antipsychotics might well cause NIDS. ${ }^{3,4}$ In the present study, haloperidol (Case 1), risperidone (Cases 1 and 3), blonanserin (Case 2), and olanzapine (Case 3) were mainly used. Haloperidol is potent typical antipsychotics, and the other agents are described as potent among atypical antipsychotics, which have dopamine $\mathrm{D}_{2}$ receptor antagonism to a certain degree.

A recent study ${ }^{10}$ indicated that disease-related deficit status might also occur in patients with bipolar disorder, not only in those with schizophrenia. As long as antipsychotics are clinically used, whether typical or atypical, the recognition and differentiation of deficit status is needed for the treatment of bipolar disorder as well as schizophrenia. When taking this problem into consideration, it is clear that NIDS is becoming an increasingly important issue in pharmacotherapy.
The authors believe that its concept should be reappraised in current clinical psychiatry.

\section{Disclosure}

The abstract of this paper was presented at the 13th International Forum on Mood and Anxiety Disorders as a poster presentation with interim findings. The poster's abstract was published in "Poster Abstracts" in International Journal of Psychiatry in Clinical Practice.

Satoshi Ueda received an honorarium from Meiji Seika Pharma Co., Ltd. The authors report no other conflicts of interest in this work.

\section{References}

1. Lader M. Neuroleptic-induced deficit syndrome: old problem, new challenge. J Psychopharmacol. 1993;7(4):392-393.

2. Lewander T. Neuroleptic and the neuroleptic-induced deficit syndrome. Acta Psychiatr Scand Suppl. 1994;380:8-13.

3. Artaloytia JF, Arango C, Lahti A, et al. Negative signs and symptoms secondary to antipsychotics: a double-blind, randomized trial of a single dose of placebo, haloperidol, and risperidone in healthy volunteers. Am J Psychiatry. 2006;163(3):488-493.

4. Park CH, Park TW, Yang JC, et al. No negative symptoms in healthy volunteers after single doses of amisulpride, aripiprazole, and haloperidol: a double-blind placebo-controlled trial. Int Clin Psychopharmacol. 2012;27(2):114-120.

5. Machida N, Shiotsuka S, Semba J. [A case of obsessive-compulsive disorder associated with neuroleptic-induced deficit syndrome (NIDS): successfully treated by discontinuation of neuroleptics followed by SSRI.] Seishin Shinkeigaku Zasshi. 2005;107(7):667-673. Japanese.

6. Mankad MV, Beyer JL, Weiner RD, Krystal AD. Clinical Manual of Electroconvulsive Therapy. Washington, DC: American Psychiatric Publishing Inc; 2010.

7. Swartz CM, Shorter E. Psychotic Depression. Cambridge, UK: Cambridge University Press; 2007.

8. Gervin M, Browne S, Garavan J, Roe M, Larkin C, O'Callanghan E. Dysphoric subjective response to neuroleptics in schizophrenia; relationship to extrapyramidal side effects and symptomatology. Eur Psychiatry. 1999;14(7):405-409.

9. Karamatskos E, Mulert C, Lambert M, Naber D. Subjective well-being of patients with schizophrenia as a target of drug treatment. Curr Pharm Biotechnol. 2012;13(8):1490-1499.

10. Nio S, Suzuki T, Uchida H, Watanabe K, Mimura M. Deficit status in bipolar disorder: investigation on prevalence rate and description of seven cases. J Affect Dis. 2012;143(1-3):248-252.
Neuropsychiatric Disease and Treatment

\section{Publish your work in this journal}

Neuropsychiatric Disease and Treatment is an international, peerreviewed journal of clinical therapeutics and pharmacology focusing on concise rapid reporting of clinical or pre-clinical studies on a range of neuropsychiatric and neurological disorders. This journal is indexed on PubMed Central, the 'PsycINFO' database and CAS,
Submit your manuscript here: http://www.dovepress.com/neuropsychiatric-disease-and-treatment-journal

and is the official journal of The International Neuropsychiatric Association (INA). The manuscript management system is completely online and includes a very quick and fair peer-review system, which is all easy to use. Visit http://www.dovepress.com/testimonials.php to read real quotes from published authors. 